\title{
Termoelektrik Soğutma Sisteminin Alternatif Transformatör Soğutma Sistemi Olarak Performansı
}

\author{
Murat Tören $^{1 *}$, Hakkı Mollahasanoğlu²

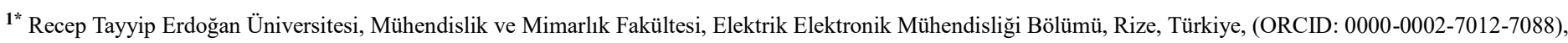 \\ murat.toren@erdogan.edu.tr \\ ${ }^{2}$ Recep Tayyip Erdoğan Üniversitesi, Mühendislik ve Mimarlık Fakültesi, Elektrik Elektronik Mühendisliği Bölümü, Rize, Türkiye (ORCID: 0000-0001-6233-9198), \\ hakki.mollahasanoglu@erdogan.edu.tr
}

(International Conference on Design, Research and Development (RDCONF) 2021 - 15-18 December 2021)

(DOI: 10.31590/ejosat.1039820)

ATIF/REFERENCE: Tören, M. \& Mollahasanoğlu, H. (2021). Termoelektrik Soğutma Sisteminin Alternatif Transformatör Soğutma Sistemi Olarak Performans1. Avrupa Bilim ve Teknoloji Dergisi, (32), 498-507.

\section{$\ddot{O} \mathbf{z}$}

Dağıtım transformatörleri kullanıldıkları yerlere göre farklı soğutma sistemleri ile soğutulmakta olup, soğutma tipine göre yağlı tip ve kuru tip transformatörler olarak isimlendirilmektedir. Yağlı tip transformatörlerin soğutulmasında, klasik transformatör yağı olarak adlandırılan naftanik ve parafinik yağlar, yani parafin (mum) içerikli dielektriksel dayanımı yüksek yalıtım malzemeleri kullanılmaktadır. Bu yağların yanma dereceleri ve dielektriksel dayanımlarının arttırılmasını amaçlayan yenilikçi yaklaşımlar son yıllarda artmaktadır. Bu çalışmalarda, daha iyi özelliklere sahip ester bazlı yağlar, klasik transformatör yağlarının yerine kullanılarak transformatörlerin performansını ve faydalı ömrünü arttıran sonuçlar elde edilmiştir. Ancak, transformatör yağlarının özellikleri ne kadar iyi olsa da, çevre kirliliği oluşturması, yanma-patlama özelliği, bakım-onarım maliyetleri, transformatör yalıtımında dezavantaj oluşturmaktadır. Bu dezavantajların giderilmesi için, bu çalışmada, çevre dostu ve yenilenebilir enerji kaynaklarından olan termoelektrik soğutucular kullanılarak, yağlı tip transformatör soğutulmaktadır. Yapılan çalışma sonucunda termoelektrik soğutma sisteminin naftanik ve ester bazlı yağ soğutma tiplerine göre yaklaşık \% 15-20 daha iyi soğutma sağladığı tespit edilmiştir. Bu soğutma sisteminin, transformatör soğutma sistemleri içerisinde yeni bir teknoloji ve tür olarak yer alacağı değerlendirilmektedir.

\section{Performance of Thermoelectric Cooling System as an Alternative Transformer Cooling System}

\begin{abstract}
Distribution transformers are cooled by different cooling systems according to the places in which they are used, and they are named oil-type and dry-type transformers according to this cooling type. In the cooling of oil-type transformers naphtanic and paraffinic oils, namely paraffin (wax)-containing insulating materials with high dielectric strength, called classical transformer oil, are used. Innovative approaches aiming to increase the degree of combustion and dielectric strength of these oils have been increasing in recent years. In these studies, higher quality oils such as ester-based oils have been used instead of conventional transformer oils, resulting in increased effects on the performance and life time of transformers. However, regardless of the characteristics of transformer oils, their features such as burning-explosive properties that cause environmental pollution and excess maintenance-repair costs create disadvantages in their use in transformer insulation. In this study conducted to eliminate such disadvantages, the oil-type transformers is cooled by using thermoelectric coolers, which are environmentally friendly and renewable energy sources. As a result of the study, it was determined that the thermoelectric cooling system provides $15-20 \%$ better cooling than naphtanic and ester based oil cooling types. It is considered that this will take place as a new technology and type in distribution transformer cooling systems.
\end{abstract}

Keywords: Oil-type transformers, Ester-based oils, Naphtanic-based oils, Thermoelectric cooler, TEC, Cooling systems.

\footnotetext{
*Sorumlu Yazar: murat.toren@erdogan.edu.tr
} 


\section{Giriş}

Elektrik üretim, iletim ve dağıtım şebekesinin en önemli ekipmanlarından biri şüphesiz transformatörlerdir. $\mathrm{Bu}$ yüzden transformatörlerin güvenli ve verimli çalışması elektrik şebekesinin güvenliği için kritik bir öneme sahiptir. Transformatörlerin çalışması esnasında çekirdek ve sargılarında meydana gelen elektriksel kayıplar, transformatörde sıcaklığın artmasına neden olmaktadır. Dolayısıyla bu sıcaklık artışı transformatörün arızalanmasına, kullanım ömrünün azalmasına, verimsiz ve güvensiz çalışmasına sebep olmaktadır. Bu durumu önlemek için, çeşitli soğutma teknikleri kullanılmaktadır.

Uzun yıllardır, özellikle dağıtım transformatörlerinin soğutulması ve yalıtılması amacıyla naftanik yağlar kullanılmaktadır (Filho et al., 2019). Yapılan birçok çalışmada naftanik yağların, transformatörlerin çalışmasına etkisi, elektriksel özelliklerinin değişimi incelenmiştir (Lamarre et al., 1987; Xiaobo Wang et al., 2018). Bu çalışmalarda, transformatörün soğutulmasında kullanılan naftanik yağların, elektriksel iletkenlik ve dielektrik dayanımının doğrudan transformatör ömrüne etki ettiği gösterilmektedir. Ayrıca farklı tip naftanik yağlar kullanılarak, yağlı tip transformatörün performansına etkisinin karşılaştırmalı olarak incelendiği çalışmada, farklı birleşim oranlarına sahip mısır yağı ile karıştırılmış mineral yağ incelenmiştir (Manjang et al., 2019). Mineral yağa, mısır yağı karışımının eklenmesiyle viskozite, özgül ağırlık ve kırılma indisinde artış tespit edilmiştir.

Son y1llarda ise yağlı tip transformatölerin soğutulmasında ester bazlı yağlar daha sıklıkla tercih edilmektedir (Rouabeh et al., 2019). Bunun başlıca nedenleri, ester bazlı yağların naftanik yağlara göre daha az yangın riski içermesi, daha uzun kullanım ömrü sağlaması ve biyolojik olarak parçalanabilmesi dolayısıyla çevreye daha faydalı olmasıdır (Dombek et al., 2017). Ester yağlar ile naftanik yağların karşılaştırıldığı çalışmalarda; ester yağların termal performans değerleri ile dielektrik dayanımının naftanik yağlara göre daha üstün olduğu, belirli konumlar arasında ester ile soğutulan transformatörün mineral yăg ile soğutulandan daha yüksek bir sıcaklık farkı gösterdiği gözlemlenmiştir (Garelli et al., 2021). Ayrıca, ester yağların, transformatörlerin yalıtım seviyesini iyileştirdiği, hatta yağın bozulma süresini geciktirdiği belirlenmiştir (Rao et al., 2018). Soğutma performansını arttırmak için, ester yağlara farklı konsatrasyona sahip katı nano parçacıklar eklenerek hibrit soğutma önerilmiştir (Hasan et al., 2020). Çalışma sonucunda, ester yağ ile en iyi soğutma yapan nanopartiküllerin Sic olduğu bulunmuş ve bunun nedeninin Sic'in diğer partiküllere göre daha yüksek 1sıl iletkenliğe sahip olduğu belirtilmiştir. Önerilen hibrit yağ sistemi ise, sıcaklığ $10{ }^{\circ} \mathrm{C}$ düşürmüştür.

Yağlı tip transformatörlerin soğutulması için ester yağlar hala daha yaygın olarak kullanılsa da, bazı dezavantajları vardır. Özellikle yüksek güç düzeylerinde kolay oksitlenebilme, yıldırıma karşı asgari direnç gösterme ve hidrolizi olabilmeleri, başlıca dezavantajları olarak gösterilebilir (X. Wang et al., 2008). $\mathrm{Bu}$ yüzden, bazı çalışmalarda ester bazlı yağlara katkı maddelerinin eklenmesi, yağın kimyasal yapısının değiştirilmesi ve yağlarla uyumlu transformatör tasarımlarının yapılması dâhil olmak üzere, farklı çalışmalar da yapılmıştır (Ab Ghani et al., 2018). Ancak, transformatörlerin soğutulması kullanılan yağların, tam olarak çevre dostu olmaması, bakım maliyetlerinin fazla olması nedeniyle, bu çalışmada yağlı tip transformatörün soğutulmasında Termoelektrik soğutucuların (TEC) kullanılması önerilmektedir.

Termoelektrik soğutma, iki yariiletken malzemenin elektriksel ve termal olarak bağlanmasıyla oluşan devreye, gerilim uygulandığında meydana gelen peltier etkisinden kaynaklanmaktadır. Termoelektrik soğutucular, uzun ömürlü olmaları, herhangi bir bakım gerektirmemeleri, küçük olmaları, zararlı çalışma sıvısı içermemeleri ve konvansiyonel sistemlerin kullanılamadıkları yerlerde çalışabilmelerinden dolayı soğutma alanında önemli bir yere sahip olmuşlardır (Cai et al., 2019; Sekiguchi et al., 2018). Ayrica, Peltier etkisi sayesinde, herhangi bir mekanik güce gerek kalmadan soğutma yapabilmeleri, gürültüsüz çalışmalarını sağlamaktadır. Bununla birlikte, soğutma kapasitesini arttırmak için termeelektrik soğutuculara fan takılmalı ve fan hızı arttırılarak, daha iyi bir soğutma sağlanabilmektedir (Jiang et al., 2019). Yapılan çalışmalarda, genellikle, termoelektrik soğutucuların performansı, verimlerinin arttırılması, parametrelerinin iyileştirilmesi ve termoelektrik etkilerinden bahsedilmektedir (Ahiska et al., 2009; Hubbard et al., 2020). Yeni imal edilen bir termoelektrik cihazın özelliklerinin incelendiği çalışmada, Si elementi ile karşılaştırma yapılmış ve termoelektrik soğutucunun 5 kat daha iyi performans sağladığ1 belirlenmiştir (Hsin et al., 2019). (Ahıska et al., 2013), yaptıkları testlerde, iki fazlı termoelektrik CPU soğutucusu, fanlı sisteme kıyasla yaklaşık 5 kat daha fazla soğutma sağladığını göstermişlerdir. Ayrıca yapılan bir başka çalışmada, termoelektrik soğutucularda nano akışkan malzeme kullanılarak, soğutma gücünün arttırıldığı, deneysel çalışma ile belirlenmiştir (Cuce et al., 2020). Başta yenilenebilir enerji uygulamaları olmak üzere, endüstriyel birçok alanda soğutma amaçlı kullanılan termoelektrik soğutucuların, çok az sayıda çalışmada (Dalcali et al., 2016; Dmitriev et al., 2017), elektrik makinalarının soğutulmasında kullanıldığı görülmüştür. Ancak, bu çalışmalarda da elektrik makinalarının soğutulmasında direkt olarak değil ek bir soğutma olarak tercih edilmişlerdir. (Toren et al., 2021)'de ise 3-fazlı asenkron motorun soğutulmasında direkt olarak termoelektrik soğutucular kullanılmış ve geleneksel hava soğutmaya göre yaklaşık \%11 daha iyi soğutma sağlanmıştır. Ancak, Termoelektrik soğutucuların, statik elektrik makinesi olan ve sıcaklık standartları dikkate alınarak tasarlanan yağlı tip transformatörlerde yaygın bir kullanımı belirlenememiştir.

Bu çalışmada, 5 kVA yağlı tip transformatör, gerçekleştirlen özgün bir tasarım ile termoelektrik soğutucular ile soğutulmaktadır. Elde edilen sonuçlar, aynı transformatörün soğutulmasında kullanılan naftanik ve ester yağlar ile karşılaştırılmaktadır. Böylece, yaygın olarak kullanılan yağlı tip transformatörlerin soğutulmasında çevre dostu, yenilenebilir enerji ürünü olan termolektrik soğutucular kullanılarak, alternatif bir soğutma yöntemi önerilmektedir.

\section{Materyal ve Metot}

\subsection{YTT Soğutma Sistemleri}

Yağlı tip transformatörler, çalışma esnasında, 1sı çekirdek kayıpları, sargılarda meydana gelen bakır kayıpları ve kaçak akım kayıplarından kaynaklı bol miktarda 1sı üretir. Bu kayıplardan, transformatördeki manyetik malzemenin histerisiz etkisinden dolay1 meydana gelen kayılar $\left(P_{h}\right)$ Denklem 1 'de ifade edilmektedir. Denklem 2'de ise, transformatörlerin ısınmasına neden olan bir diğer çekirdek kaybı olan fuko kayıpları $\left(P_{e}\right)$ ifade edilmektedir. $\mathrm{Bu}$ kayıplar, bobin üzerinden değişken akım 
akıtıldığında, gövde üzerinden endüklenen gerilimin, sebep olduğu akımlardır (Toren et al., 2016).

$$
P_{h}=\sigma_{h} f B_{m} G_{f e}
$$

Burada, $\sigma_{h}, f, B_{m}$ ve $G_{f e}$ sırasıyla, histerezis kayıp faktörü, frekans değeri, akı yoğunluğu ve demir çekirdek kütlesini ifade etmektedir.

$$
P_{e}=\sigma_{e} f^{2} B_{m}^{2} G_{f e}
$$

Denklem 2'de, $\sigma_{e}$, malzemeye bağlı olarak değișen Eddy sabitidir. Transformatörlerin sargılarından geçen akımın (I) meydana getirdiği kayıplar ise, bakır kayıpları olarak adlandırılıp, Denklem 3'te verilmektedir.

$$
P_{c u}=I^{2} R
$$

Transformatörlerin çalışması esnasında, tüm bu kayıplardan dolayı meydana çıkan 1sı, transformatörün yüksek bir sıcaklığa ulaşmasına izin verilmeden transfer edilmelidir. Bu nedenle, 1sıyı transfer etmek için transformatörlerin soğutulması gerekmektedir. Yağlı tip transformatörlerin soğutulması ve buna uygun olarak tasarlanmas1, IEEE C57.91-1995 ve IEC 60354 endüstri standartları dikkate alınarak belirlenmektedir (Perez, 2010). Bu standartalara göre belirlenen başlıca soğutma türleri aşağıda sıralanmaktadır (Kaymaz et al., 2015):

- ONAN (Oil Natural Air Natural), doğal hava ile soğutulan sargilar ile isınan yağın doğal sirkülasyonunu ifade etmektedir.

- ONAF (Oil Natural Air Forced), hava temasının fan ile, yağ dolaşımının konvansiyonel olarak sağlandiğı soğutma türüdür.

- OFAF (Oil forced Air forced), konvansiyonel sisteme ilave olarak, yağın sirkülasyonu yağ pompaları ile de desteklenen soğutma türüdür. Ayrıca doğal hava için fanlar da kullanılır.

- OFWF (Oil forced Water forced), konvansiyonel olarak sağlanan yağ soğutma ile birlikte su soğutmanın da kullanılmasını ifade etmektedir.

- ODAF (Oil directed Air forced), direkt olarak yağın nüve ve bobine teması ile sağlanan, ayrıca fan ile havanın da soğutmaya katıldığı sistemi ifade etmektedir.

- ODWF (Oil directed Water forced), direkt olarak yağın nüve ve bobine teması ile sağlanan, ayrıca suyun da soğutmaya katıldığı sistemi ifade etmektedir.

$\mathrm{Bu}$ soğutma sistemleri, yağlı tip transformatörlerin kullanıldığı yere, tasarımına veya boyutuna göre değişmektedir. Ayrıca soğutma da kullanılan yağ türünün de soğutma sistemleri üzerinde etkisi vardır. Aynı şekilde kullanılan soğutma sistemlerinin de transformatör tasarımları üzerinde etkisi vardır. $\mathrm{Bu}$ yüzden, bu çalışmada, yağlı tip transformatörün soğutulması için önerilen yöntem için de özgün bir prototip tasarlanmıştır. Tasarlanan, özgün yağlı tip transformatörün teknik özellikleri Tablo 1'de verilmektedir. Tablo 2'de ise YTT'nin soğutulmas1 için kullanılan naftanik ve ester bazlı yağların teknik özellikleri

\begin{tabular}{|c|c|c|}
\hline \multicolumn{2}{|l|}{ Karakteristik } & \multirow{2}{*}{$3 \sim 5 \mathrm{kVA}$ YTT } \\
\hline Parametre & Birim & \\
\hline Güç & VA & 5000 \\
\hline Primer Sargl Gerilimi & $\mathrm{V}$ & 380 \\
\hline Sekonder Sargl Gerilimi & $\mathrm{V}$ & 220 \\
\hline Frekans & $\mathrm{Hz}$ & 50 \\
\hline Sargl Grubu & - & Yzn-11 \\
\hline Standartlar & - & IEC 60076-11 \\
\hline Nominal gerilimdeki empedans & $\%$ & 6.0 \\
\hline Soğutma & - & Yağ ve TEC \\
\hline Sargı İletken Türleri & - & Bakır \\
\hline
\end{tabular}
verilmektedir.
Tablo 1. Çalışmada Kullanılan YTT Özellikleri

Tablo 1'de özellikleri verilen YTT için tasarlanan özgün modelin fiziki görünümü Şekil 1'de verilmiştir.

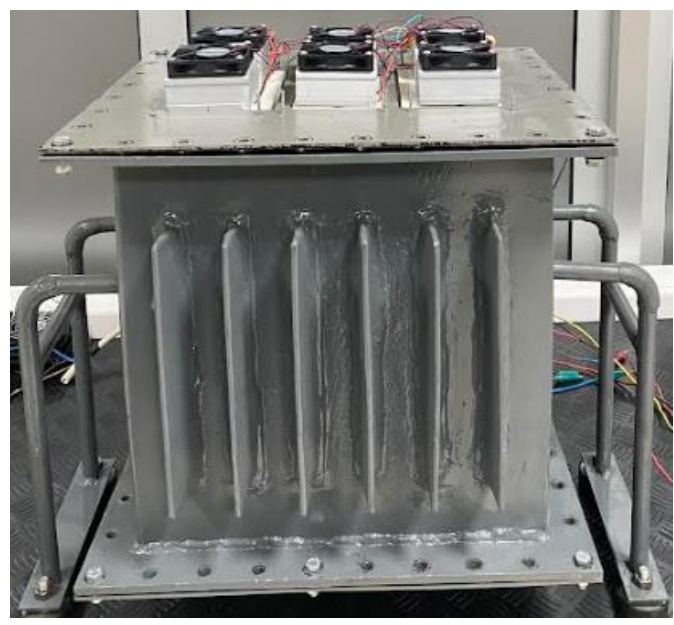

Şekil 1. YTT'nin fiziki görünümü

Termoelektrik soğutucular ile YTT'nin soğutulmasını için transformatörün üst kısmına TEC modüller ile oluşturulan soğutucu blokların montajı yapılmıştır. Söz konusu TEC modüllerin görünümü Şekil 2'de verilmiştir.

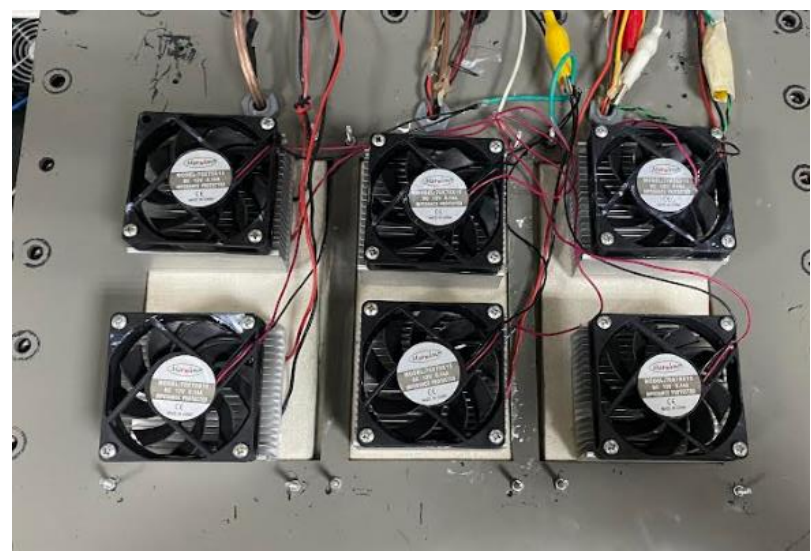

Şekil 2. TEC soğutucu modüller 
Tablo 2. Çalışmada kullanılan yağların özellikleri (Shell Diala S4 ZX-I Trafo Yă̆g, n.d.; Trafo Yağı, n.d.)

\begin{tabular}{|c|c|c|c|}
\hline Özellik & Standartlar & Naftanik Yăg & Ester Bazlı Yağ \\
\hline Görünüş & IEC 60296 & Temiz, tortusuz & Temiz, Berrak \\
\hline Yoğunluk, $20^{\circ} \mathrm{C} \mathrm{Kg} / \mathrm{Dm}^{3}$ & ISO 12185 & Max. 0,895 & 805 \\
\hline Vizkozite, $40^{\circ} \mathrm{C} \mathrm{Mm}^{2} / \mathrm{S}$ & ISO 3104 & Max. 12 & Max. 9,9 \\
\hline Vizkozite, $-30^{\circ} \mathrm{C} \mathrm{Mm}^{2} / \mathrm{S}$ & ISO 3104 & Max. 1800 & Max. 523 \\
\hline Akma Noktasi, ${ }^{\circ} \mathrm{C}$ & ISO 3016 & Max. -40 & Max. -42 \\
\hline Dielektrik Dağitma Faktörü (Ddf)@ $90^{\circ} \mathrm{C}$ & IEC 60247 & Max. 0,005 & Max. 0,001 \\
\hline Bozulma Gerilimi-Isslem Öncesi, Kv & IEC 60156 & Min. 30 & Min. 70 \\
\hline Bozulma Gerilimi-Işlem Sonrası, Kv & IEC 60156 & Min. 70 & Min. 78 \\
\hline Çamur, Wt\% - @ 120 ${ }^{\circ} \mathrm{C}, 164 \mathrm{Sa}$ & IEC 61125 & Max. 0,8 & Max. 0,001 \\
\hline$D d f / 90^{\circ} \mathrm{C}-@ 120^{\circ} \mathrm{C}, 164 \mathrm{Sa}$ & IEC 61125 & Max. 0,5 & Max. 0,5 \\
\hline Alevlenme Noktasi, $\mathrm{Pm},{ }^{\circ} \mathrm{C}$ & ISO 2719 & Min. 135 & Min. 191 \\
\hline
\end{tabular}

\subsection{Termoelektrik Soğutucular}

Termoelektrik soğutucular, iki farklı yarı iletken malzemenin elektriksel olarak seri ve termal olarak paralel bağlanmasıyla oluşturulur. Şekil 3'te gösterildiği gibi, p ve n tipi yariiletken malzemeler ve 1sıl iletkenliğe sahip seramik yüzeyler ile devre oluşturulöaktadır.

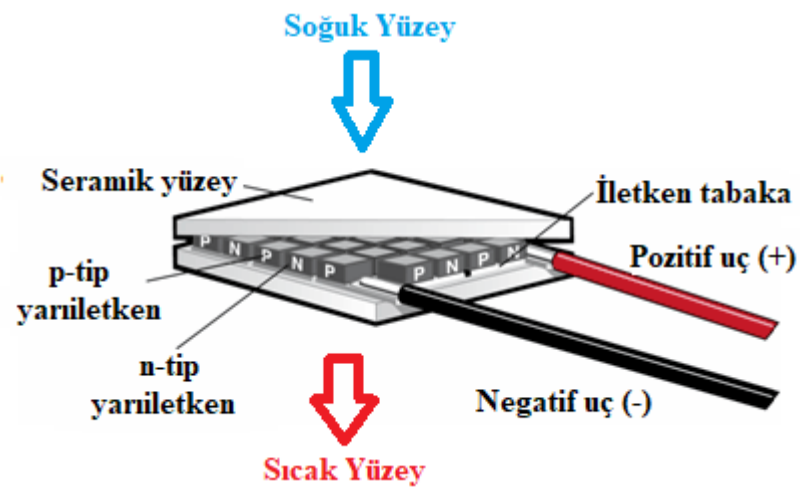

Şekil 3. Termoelektrik soğutucu yapısı

Şekil 3'te verilen termoelektrik soğutucu üzerine DA uygulandığında, Peltier etkisi ile 1sı transferi gerçekleşir ve seramik yüzeyler arasında sıcaklık farkı meydana gelir. Böylece TEC modülün bir yüzü ortam sıcaklığının altına inerken diğer yüzü ise ortam sıcaklığının üzerine çıkar. Bu sıcaklık ve akım ilişkisi Denklem 4'te gösterilmektedir.

$$
\pi=q / I
$$

Bu eşitlikte $\pi, q$ ve $I$ sırasıyla, peltier katsayısını, Peltier 1sısını ve devreye uygulanan akımı ifade etmektedir. Peltier etkisinin kullanıldığı sistemlerde soğutma sağlanması için peltier katsayısının yüksek olması beklenmektedir.

Termoelektrik soğutucuların performansını belirlemek için kullanılan bazı büyüklükler vardır. Bunlardan en yaygın olarak kullanılanı COP değeridir. Bu değer, önemli bir karşılaştırma büyüklüğü olup, soğutma gücünün elektrik tüketimine oranı olarak ifade edilmektedir. Denklem 5'te COP değeri gösterilmektedir.

$$
C O P=q / W
$$

$W$ değeri elektrik tüketimidir. COP değeri ne kadar fazla olursa, soğutma o kadar artacaktır (Koh et al., 2014).

Bu çalışmada, termoelektrik soğutucu olarak, TEC1-12706 Peltier modülü kullanılmıştır. Tablo 3 'te bu modülün teknik özellikleri ve Şekil 4'te COP performans grafiği verilmektedir (Specification of Thermoelectric Module, n.d.).

Tablo 3. TEC1-12706 peltier teknik özellikleri

\begin{tabular}{l|c|c}
\hline \multicolumn{1}{c|}{ Parametre } & \multicolumn{2}{c}{ Değer } \\
\hline Sicak Yüzey Sicaklı̆̆ı. $\left({ }^{\circ} \mathrm{C}\right)$ & 27 & 50 \\
\hline$Q_{\max }($ Watt $)$ & 61.4 & 66.7 \\
\hline$\Delta T_{\max }\left({ }^{\circ} \mathrm{C}\right)$ & 70 & 79 \\
\hline$I_{\max }(A)$ & 6.1 & 6.1 \\
\hline$V_{\max }(V)$ & 16 & 17.2 \\
\hline Resistance $(\Omega)$ & 2 & 2.2 \\
\hline Tolerans & \multicolumn{2}{|c}{ \pm 10} \\
\hline
\end{tabular}

Performance Curves at $\mathrm{Th}=27^{\circ} \mathrm{C}$

Performance Curves at $\mathrm{Th}=\mathbf{5 0}{ }^{\circ} \mathrm{C}$
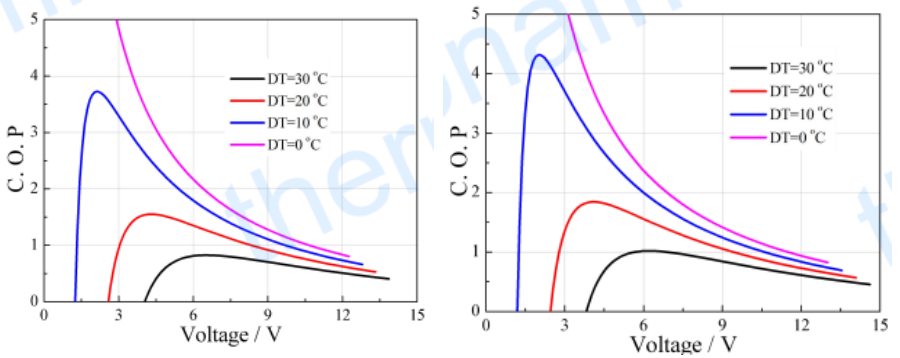

Şekil 4. TEC1-12706 COP grafiği (Sıcaklık farkı: 0-30 ${ }^{\circ} \mathrm{C}$ )

Termoelektrik soğutucunun optimum çalışma noktası, COP değerinin maksimum olduğu zamandır. Tasarlanacak sistemde iç ve dış yüzeyler arasındaki sıcaklık farkına göre optimum çalışma durumu belirlenir. Ayrıca, soğutulacak hacmin ısıl yüküne ve her bir soğutucu Peltier modülünden elde edilebilecek maksimum soğutma gücüne göre, tasarımda kullanılacak Peltier modülünün sayısı belirlenir.

Bu çalışmada, 5 kVA yağlı tip transformatörün soğutulması amacıyla 6 adet TEC1-12706 Peltier modülü kullanılmıştır. Her 
bir Peltier, Şekil 5'te gösterildiği gibi iki alminyum soğutucu radyatör ile fan arasına yerleştirilerek, soğutucu bloklar oluşturulmuştur.

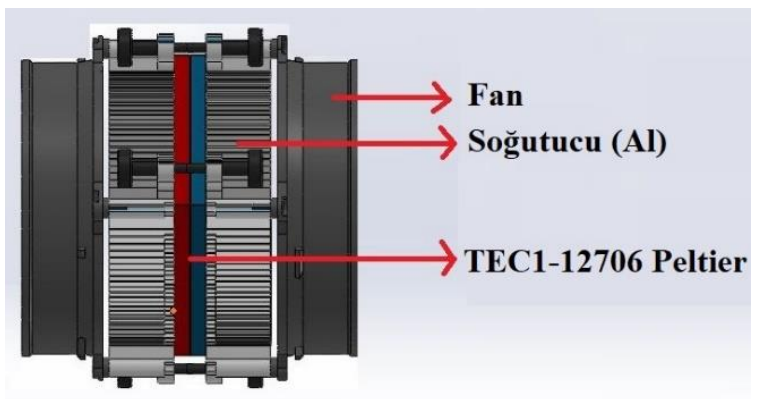

Şekil 5. Termoelektrik soğutucu blok yapısı

Bir modülün maksimum soğutma gücü ise modülün katalog (etiket) değeri olmayıp, atılan ısının uzaklaştırılma etkinliğine şiddetle bağlıdır. Bu nedenle bir Peltier modülün üzerinde yazan maksimum soğutma gücünün çok altında değerlerle pratikte karşılaşılabilmektedir.

\section{Araştırma Sonuçları ve Tartışma}

\subsection{YTT Soğutma Sistemi Deney Düzeneği}

5 kVA gücündeki YTT'nin nominal çalışma koşullarında, soğutulması için farklı yalıtım materyallerine göre hazırlanan deney şeması Şekil 6 ve 7'de gösterilmiştir. Deney ortamındaki ortam sıcaklığı, IEEE C57.91-1995 standardı dikkate alınarak, 30 ${ }^{\circ} \mathrm{C}$ olarak sağlanmıştır. Bu deney düzeneğinde, $5 \mathrm{kVA}-380 / 220$ V YTT, her bir faz için, primer tarafında 7,5 A, sekonder tarafinda ise 12,8 A nominal değerlerinde çalıştırılmaktadır.

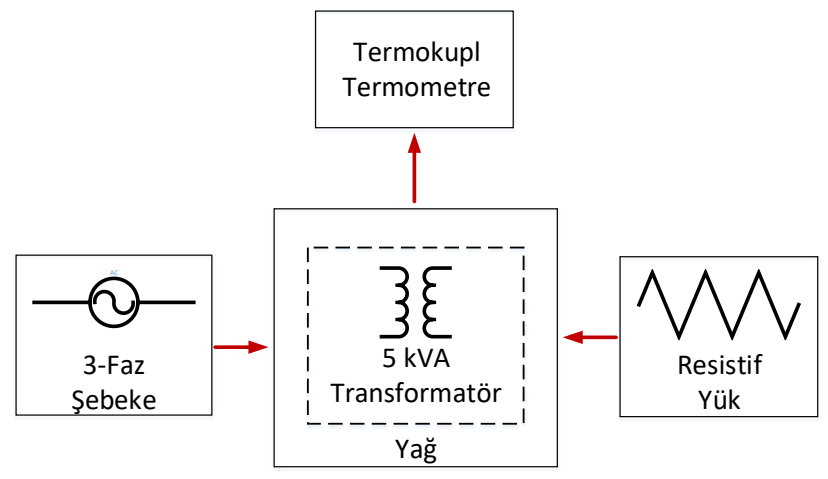

(a)

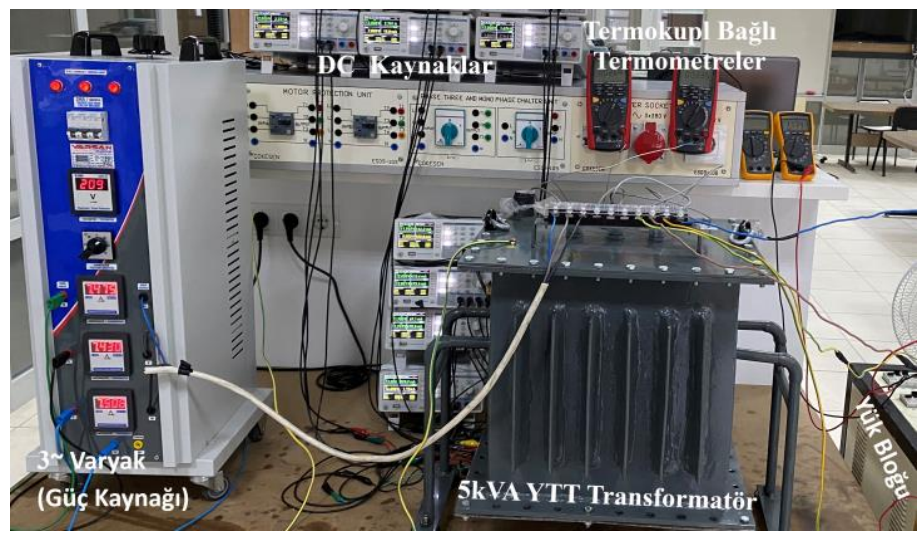

(b)

Şekil 5. YTT’nin yă̆ ile soğutulması: Blok şeması (a) ve deney düzeneği (b)
Şekil 5, YTT'nin soğutulması için naftanik yağ ve ester bazlı yağın kullanıldığı deney düzeneğini göstermektedir. Bu deney düzeneği kullanılarak, $30^{\circ} \mathrm{C}$ ortam sıcaklığında, 8 saatlik çalışma süresinde (09:00-17:00), YTT'nin; sarg1, nüve ve kabin gövdesinde meydana gelen sıcaklık değerleri elde edilmektedir. Sicaklık ölçümü için, sargı ve nüve de termokulplu termometre ve transformatör kabin gövdesinde ise termal kamera kullanılmıştır.

Şekil 6'da verilen deney düzeneğinde ise özgün olarak tasarımı gerçekleştirilen TEC modül soğutmalı sistem, YTT kabinine eklenmektedir. Bu sistem ile YTT'nin güçlendirilmiş hava soğutması ile soğutulması, yağlı soğutma sistemlerindeki aynı ortam sıcaklığı ve çalışma süresinde sargı, nüve ve kabin gövdesindeki sıcaklıklar ölçülmektedir.

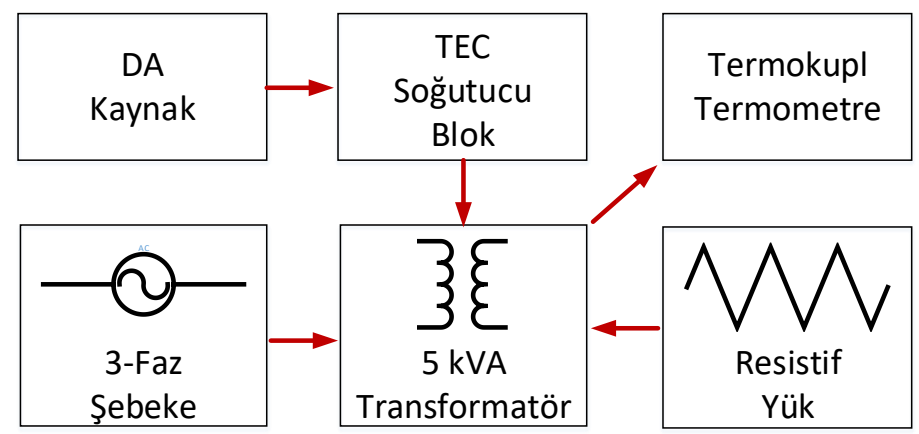

(a)

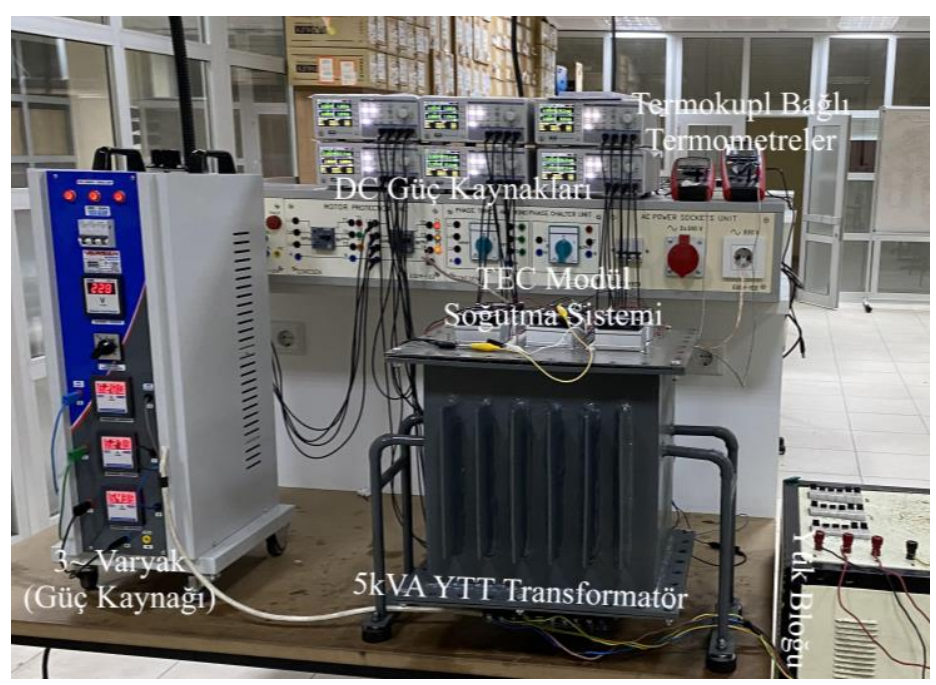

(b)

Şekil 6. YTT’nin TEC ile soğutulması: Blok şeması (a) ve deney düzene $\breve{i}($ (b)

Naftanik yağ ve ester bazlı yağın kullanıldığı deney düzeneğininde olduğu gibi, TEC soğutuculu deney düzeneği kullanılarak, $30{ }^{\circ} \mathrm{C}$ ortam sıcaklığında, 8 saatlik çalışma süresinde (09:00-17:00), YTT'nin; sarg1, nüve ve kabin gövdesinde meydana gelen sıcaklık değerleri elde edilmektedir.

YTT'nin çalışması esnasında sargılarda oluşan sıcaklık kabin havasını 1sıtmakta, ısınan hava da kabin içerisinde yukarı çıkmaktadır. Endüstride kullanılan YTT kabinlerinde hava akışı için yerleştirilen güçlendirilmiş hava sistemlerinin (fanlı sistem) kabin altında olduğu tasarımlar mevcuttur. Bu tasarımların aksine üst kısımda yükselen sıcak havayı soğutması ve genel olarak da kabin içerisinde daha iyi 1sı transferi sağlaması için TEC modül soğutma sistemi özgün tasarımda ve Şekil 6'da görüldüğü üzere 
üst konuma yerleştirilmektedir (Bu soğutma sistemi YTT ler için 1zgaralı mahfaza ile korunacaktır).

\subsubsection{YTT 'nin Naftanik Yăg ile Soğutulması ve Sonuçlar}

Şekil 5'te verilen deney düzeneği kurularak, YTT'nin kabini içerisine yaklaşık 37 lt naftanik yağ konulmuştur. YTT'nin kabin gövdesinden termal kamera ile ölçümler alınmıştır. Çalışma süresinin başında ve sonunda alınan ölçümler Şekil 7'de gösterilmektedir.
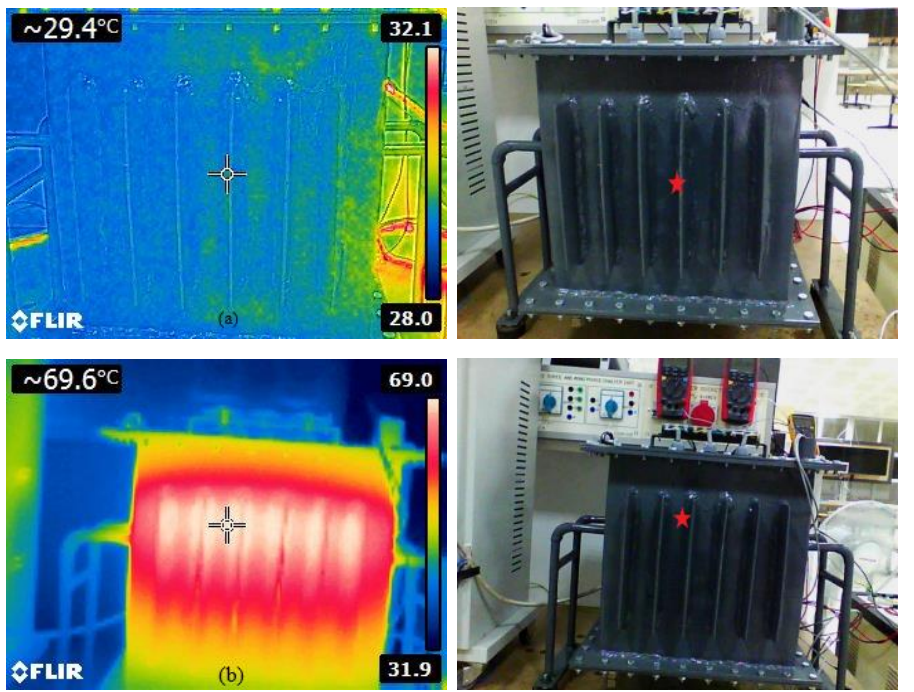

Şekil 7. Naftanik yă̆ soğutmalı YTT kabin gövde sicaklık termal kamera görüntüleri

YTT'nin nüve ve sargılarında meydana gelen ısıyı ölçmek için ilgili yerlere termokulp bağlanarak termometre ile ölçümler kaydedilmiş olup, tüm ölçümler Tablo 4 'te verilmektedir.

Tablo 4. Naftanik yă̆ soğutmalı YTT slcaklıklarl

\begin{tabular}{c|c|c}
\hline \multicolumn{3}{c}{ Naftanik Yağ Soğutmalı Yağlı Tip Transformatör } \\
\hline Sargılar $\left({ }^{\circ} \mathrm{C}\right)$ & Nüve $\left({ }^{\circ} \mathrm{C}\right)$ & Kabin Gövdesi $\left({ }^{\circ} \mathrm{C}\right)$ \\
\hline 28,1 & 29,9 & 29,4 \\
\hline 36,7 & 46 & 38,1 \\
\hline 43,8 & 58,1 & 51,8 \\
\hline 48,9 & 64,4 & 58,2 \\
\hline 52,3 & 68,2 & 60,5 \\
\hline 55 & 70,9 & 62,1 \\
\hline 56,7 & 72,7 & 64,7 \\
\hline 58,1 & 75 & 66,1 \\
\hline 58,2 & 75,5 & 69.6 \\
\hline
\end{tabular}

Burada, naftanik yağlı soğutmanın etkisiyle 8 saatlik çalışma süresinde, sargılardaki sıcaklık değeri en yüksek $58,3^{\circ} \mathrm{C}$, nüvede $75,5^{\circ} \mathrm{C}$ ve YTT kabi gövdesinde ise $69,6^{\circ} \mathrm{C}$ olmaktadır.

YTT'nin naftanik yă̆ ile soğutulmasıyla, transformatörün sarg1, nüve ve kabin gövdesinde ölçülen sıcaklık değerlerinin değişim grafiği Şekil 8'de verilmektedir.

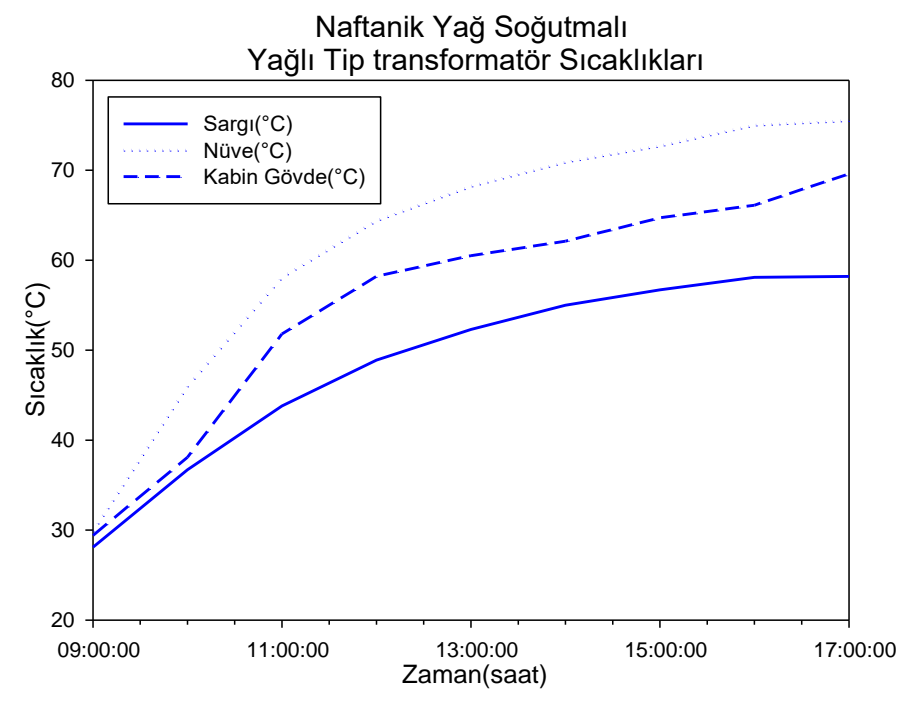

Şekil 8. Naftanik yă̆ soğutmalı YTT sıcaklık değişimleri grafiği

Şekil 8 incelendiğinde, nüve sicaklık değerlerinin sarg1 ve kabin gövde sıcaklık değerlerine göre daha yüksek sıcaklık değerinde olduğu belirlenmektedir.

\subsubsection{YTT 'nin Ester Bazlı Yă̆ ile Soğutulması ve Sonuçlar}

Bu çalışmada, YTT'nin soğutulması için naftanik yağlardan daha iyi yaltım gücüne sahip ve günümüzde yaygın olarak kullanılan Ester bazlı yağlar da kullanılmıştır. Bunun amacı klasik transformatör yağlarına göre daha iyi performans gösteren yağları kullanarak, karşıllaştırma yapmaktır.

Şekil 9'da, Ester bazlı yağ kullanılarak soğutulan YTT'nin kabin gövdesinden elde edilen termal kamera görüntüleri verilmektedir. $\mathrm{Bu}$ görüntüler transformatörün çalışma süresince alınan ilk sıcaklık değerleri ile en yüksek sıcaklık değerleridir.

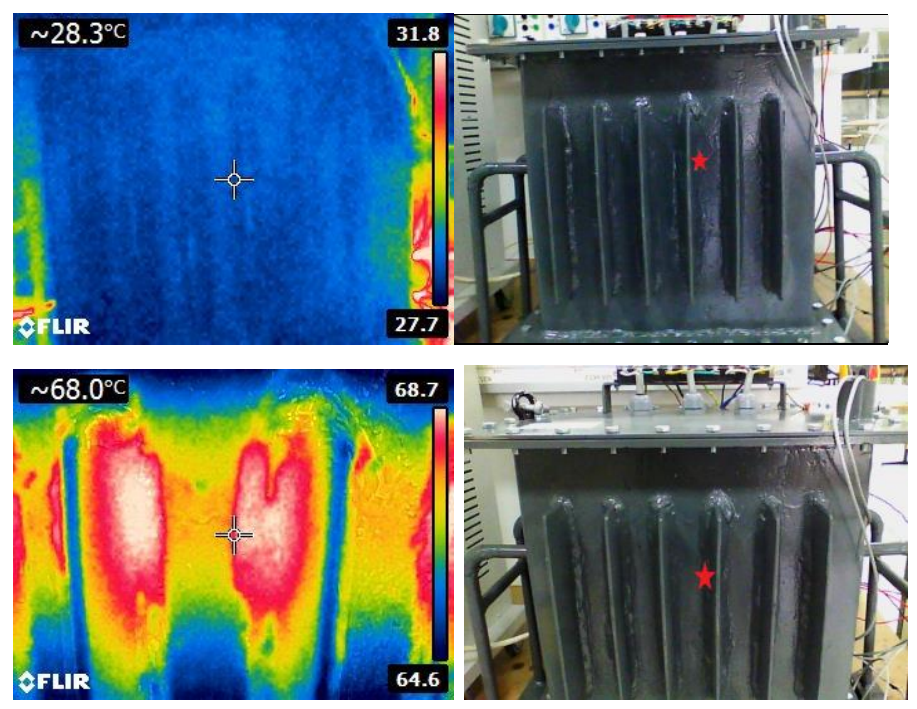

Şekil 9. Ester bazlı yă̆ soğutmalı YTT kabin gövde sıcaklık termal kamera görüntüleri

Ester bazlı yağ ile soğutulan YTT'nin nüve ve sargılarında meydana gelen 1sıyı ölçmek için ilgili yerlere termokulp bağlanarak termometre ile elde edilen ölçümler ile termal kamera ile kabin gövdesinden elde edilen ölçümler Tablo 5'te verilmektedir. 
Tablo 5. Ester bazll yăg soğutmall YTT sicakliklarl

\section{Ester Bazlı Yağ Soğutmalı Yağı Tip Transformatör}

\begin{tabular}{c|c|c}
\hline Sargılar $\left({ }^{\circ} \mathrm{C}\right)$ & Nüve $\left({ }^{\circ} \mathrm{C}\right)$ & Kabin Gövde $\left({ }^{\circ} \mathrm{C}\right)$ \\
\hline 28,8 & 29,4 & 28,3 \\
\hline 32,1 & 40,6 & 36,6 \\
\hline 43,3 & 55,4 & 51,8 \\
\hline 47,9 & 61 & 55,6 \\
\hline 50,8 & 64,9 & 59,9 \\
\hline 54 & 68,5 & 61,2 \\
\hline 55,7 & 70,6 & 63 \\
\hline 60,5 & 75,2 & 65,9 \\
\hline 61,5 & 75,5 & 68 \\
\hline
\end{tabular}

Tablo 5' incelendiğinde, elde edilen sonuçların naftanik yağ ile soğutulan transformatöre göre daha düşük sıcaklık değerleri olduğu, dolayısıyla ester bazlı yağın, naftanik yağa göre daha iyi soğutma sağladığı görülmektedir.

YTT'nin ester bazlı yağ ile soğutulmasıyla, transformatörün sarg1, nüve ve kabin gövdesinde ölçülen sıcaklık değerlerinin değişim grafiği ise Şekil 10 'da verilmektedir.

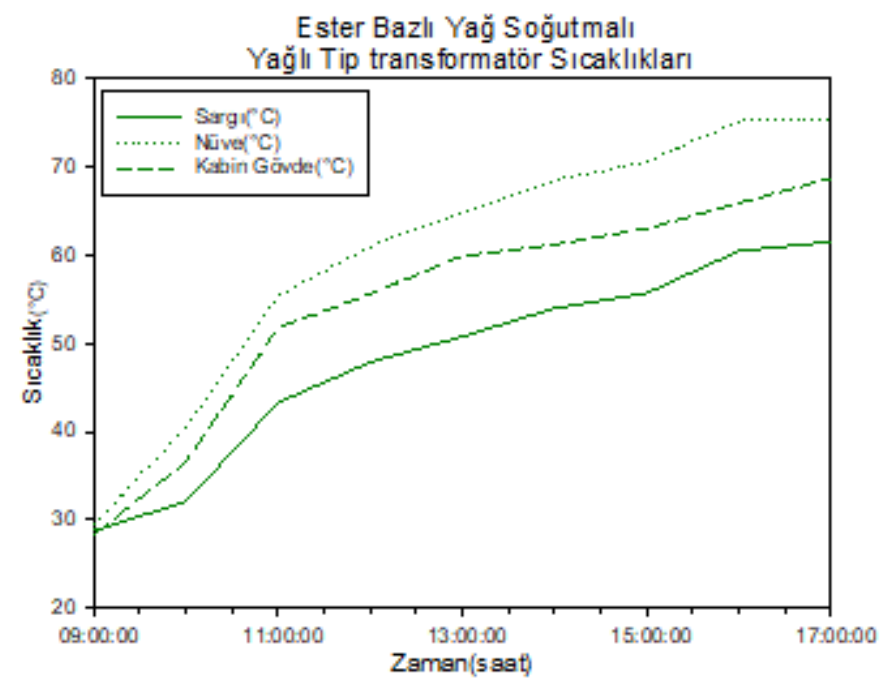

Şekil 10. Ester bazlı yăg soğutmalı YTT sıcaklık değişimleri grafiği

\subsubsection{YTT 'nin TEC Modül ile Soğutulmast ve Sonuçlar}

Yağlı tip transformatörlerin; yağ, su ve hava soğutmalı sistemler dişında standartlarda belirlenen herhangi bir soğutma sistemi tanımlanmamaktadır. Termoelektrik soğutucular, mevcut soğutma sistemlerinin olumsuz etkilerini minimize edebilecek, yenilenebilir ve çevre dostu olarak alternatif bir soğutma sistemi olarak önerilmektedir. 6 adet TEC1-12706 Peltier modülü kullanılarak oluşturulan TEC soğutucu blok YTT kabininin üst konumuna yerleştirilmiştir. Böylece daha iyi hava transferi yapılması amaçlanmıştır.

Şekil 11'de, TEC soğutucu blok kullanılarak soğutulan YTT'nin kabin gövdesinden elde edilen termal kamera görüntüleri verilmektedir. Bu görüntüler transformatörün çalışma süresince alınan ilk sıcaklık değerleri ile en yüksek sıcaklık değerleridir.

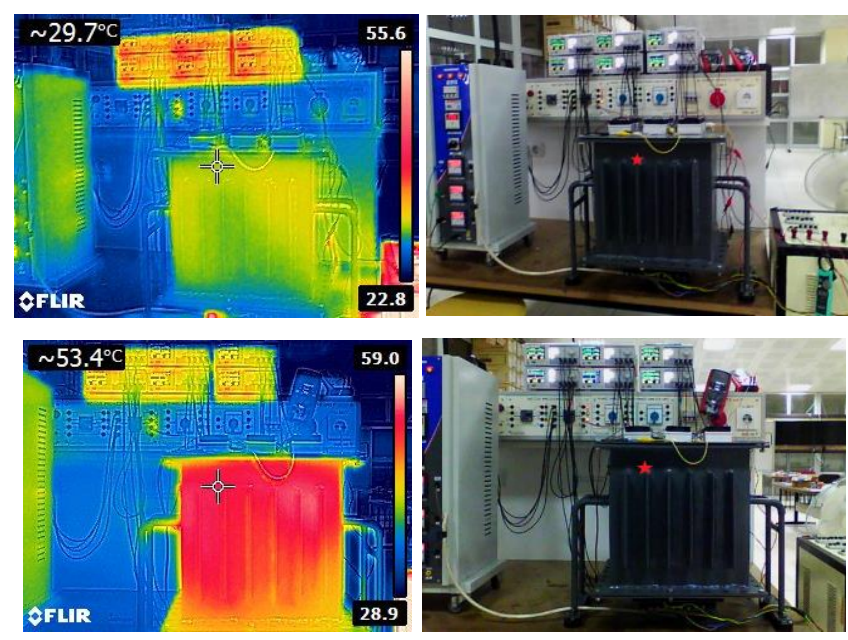

Şekil 11. TEC modül soğutmalı YTT kabin gövde sicaklık termal kamera görüntüleri

Tablo 6'da ise, YTT'nin 8 saatlik çalışma süresinde nüve, sargı ve kabin gövdesinde oluşan sıcaklık değerleri verilmektedir.

Tablo 6. TEC modül soğutma sistemli YTT sicaklıkları

\begin{tabular}{c|c|c}
\hline \multicolumn{3}{c}{ TEC Modül Soğutmalı Yağlı tip Transformatör } \\
\hline Sargılar $\left({ }^{\circ} \mathrm{C}\right)$ & Nüve $\left({ }^{\circ} \mathrm{C}\right)$ & Kabin Gövde $\left({ }^{\circ} \mathrm{C}\right)$ \\
\hline 28,5 & 26,5 & 29,7 \\
\hline 30,6 & 46,7 & 32,3 \\
\hline 38,2 & 55,7 & 34,3 \\
\hline 47,4 & 57,1 & 38,1 \\
\hline 50,6 & 66,3 & 44,8 \\
\hline 53,8 & 66,8 & 46 \\
\hline 56,4 & 70,4 & 46,5 \\
\hline 57,1 & 72,8 & 47,4 \\
\hline 57,9 & 73,5 & 53,4 \\
\hline
\end{tabular}

Burada, nüve için $73,5^{\circ} \mathrm{C}$, sargı için $57,9^{\circ} \mathrm{C}$ ve kabin gövdesi için $53,4^{\circ} \mathrm{C}$ sıcaklık değerlerinin naftanik ve ester bazlı yağ ile soğutulan transformatöre göre daha düşük sıcaklık değerleri olduğu, dolayısıyla daha iyi soğutma sağlandığı görülmektedir.

YTT'nin TEC soğutucu blok ile soğutulmasıyla, transformatörün sargı, nüve ve kabin gövdesinde ölçülen sıcaklık değerlerinin değişim grafiği Şekil 12'de verilmektedir.

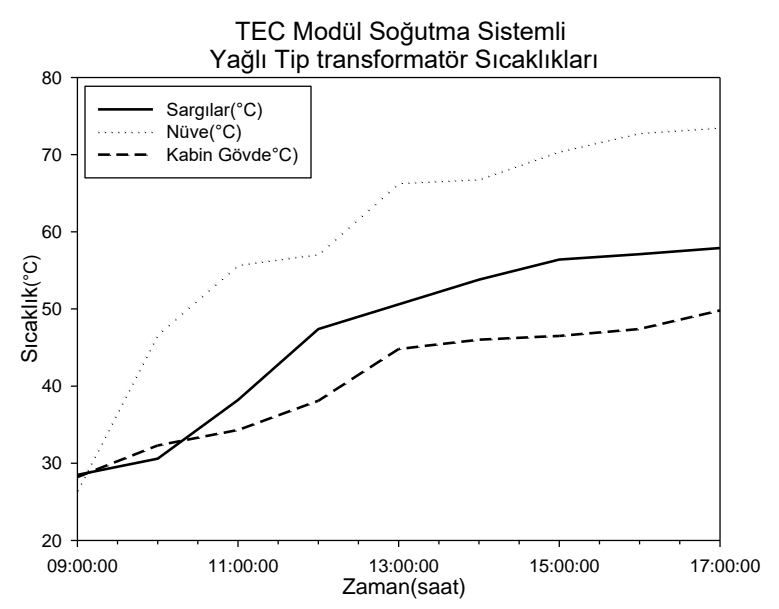




\section{Şekil 12. TEC modül soğutmalı YTT sıcaklık değişimleri grafiği}

YTT'nin soğutulmasında kullanılan TEC modüllerin transfer ettikleri ve üzerlerinde ölçülen sıcaklık değeri ise Şekil 13 'te görülmektedir.

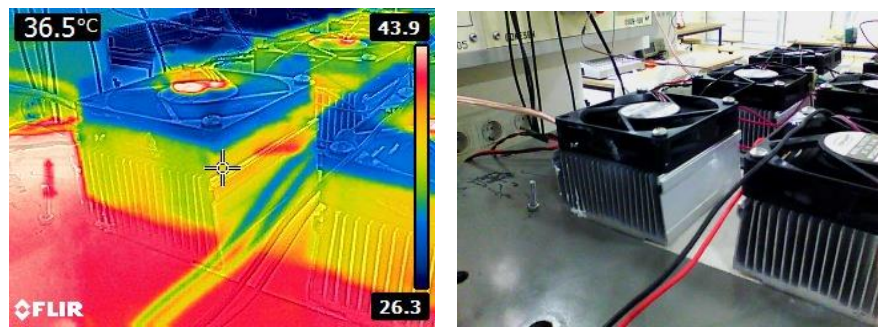

Şekil 13. TEC modülün YTT kabin gövde üzerindeki sıcakllğının termal kamera görüntüleri

Çalışma esnasında kabinde $53,4{ }^{\circ} \mathrm{C}$ sıcaklık ölçülürken aynı zamanda TEC lerden $36,5^{\circ} \mathrm{C}$ sıcaklık ölçülmektedir. Dolayısıyla TEC modüllerin YTT kabinini soğutmada etkili olduğu belirlenmektedir.

\subsection{YTT Soğutma Sistemlerinin Karşılaştırılması}

Bu çalışmada, YTT'nin soğutulması için kullanılan naftanik yağ, ester bazlı yağ ve TEC soğutma sistemlerinin transformatör üzerindeki etkileri incelenmiş̧ir. Farklı soğutma sistemleri için, YTT'nin 8 saatlik çalışma süresi sonunda, sargılarında ölçülen sicaklık değerleri Şekil 14 'te verilmektedir.

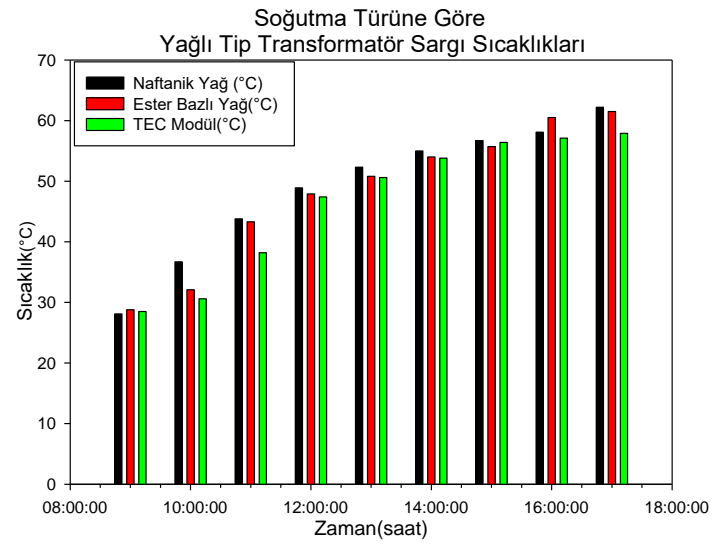

\section{Şekil 14. Farklı soğutma sistemleri için YTT sargl slcaklikları}

Şekil 14 incelendiğinde, YTT'nin sargılarında elde edilen en düşük sıcaklık değerinin TEC soğutma sistemi ile sağlandığı görülmektedir. Farklı soğutma sistemleri için, YTT'nin nüvesinde ölçülen sıcaklık değerleri ise Şekil 15 'te gösterilmiştir.

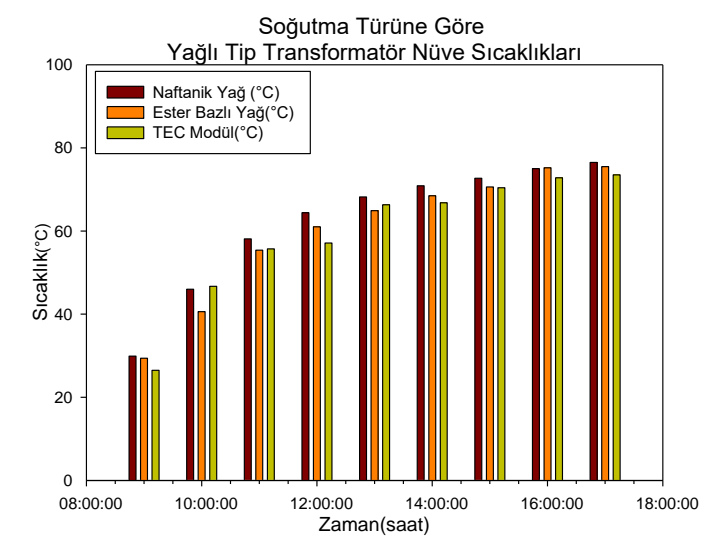

Şekil 15. Farklı soğutma sistemleri için YTT nüve sıcaklıkları
YTT'nin nüvesinde elde edilen en düşük sıcaklık değerinin sargılarda olduğu gibi, TEC soğutma sistemi ile sağlandığ görülmektedir.

Farklı soğutma sistemleri için, YTT'nin kabin gövdesinden termal kamera ile ölçülen sıcaklık değerleri ise Şekil 16 'da gösterilmiştir.

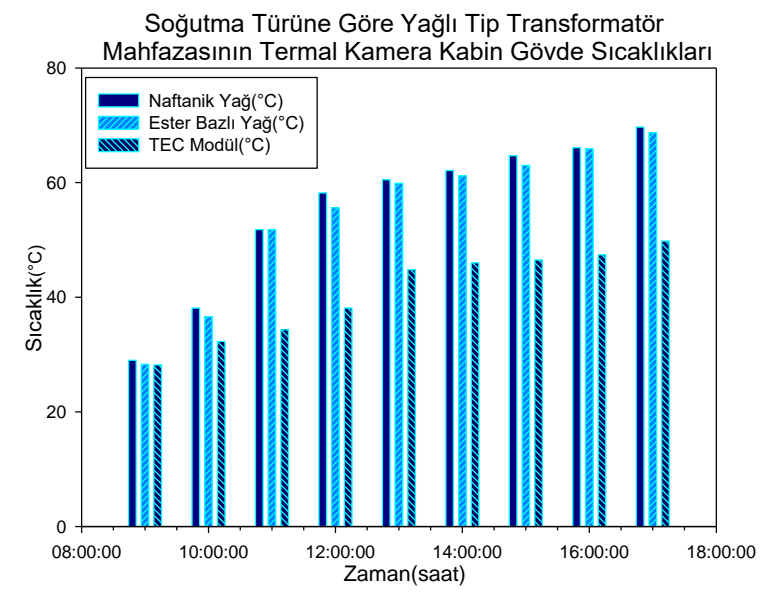

Şekil 16. Farklı soğutma sistemleri için YTT kabin gövde sicaklıkları

Sekil 16'da TEC soğutuculu sistem kullanılarak kabin gövdesinde elde edilen sıcaklık değerlerinin, diğer soğutma türlerine göre \% 15-20 oranında daha düşük olduğu, dolayısıyla daha iyi soğutma yaptığı görülmektedir.

\section{Sonuç}

Elektrik üretim, iletim ve dağıtım şebekesinin en önemli ekipmanlarından biri olan yağlı tip transformatörlerin soğutulması, hem transformatörlerin faydalı ömürleri hem de elektrik şebekesinin güvenirliliği için çok önemlidir. Ancak soğutmada yaygın olarak kullanılan naftanik ve ester bazlı yağların, çevre dostu olmaması, bakım onarım maliyetlerinin fazla olmasından dolayı, bu çalışmada yağlı tip transformatörün soğutulması için alternatif bir yöntem önerilmiştir. Önerilen yöntemde Termoelektrik soğutucuların kullanıldığı, özgün bir yağlı tip transformatör prototipi tasarlanmıştır. Tasarlanan protoip naftanik ve ester bazlı soğutma sistemlerinin yanı sıra termoelektrik soğutucu sistem ile de soğutularak, elde edilen sonuçlar karşılaştırılmıştır. Termoelektrik soğutuculu sistem kullanılarak kabin gövdesinde elde edilen sıcaklık değerlerinin, diğer soğutma türlerine göre \% 15-20 oranında daha düşük olduğu, dolayısıyla daha iyi soğutma yaptığı görülmektedir. Gerçekleştirilen bu çalışma ile yağlı tip transformatörlerin soğutulmasında geleneksel yöntemlerden farklı olarak, Termoelektrik soğutucu sistemlerin geliştirilerek kullanılabileceği değerlendirilmektedir. Böylece transformatörler için çevre dostu ve yenilenilir enerji ürünü olan yeni bir soğutma sınıfi oluşturulabilecektir.

\section{Teșekkür}

Bu çalışma TÜBİTAK, $121 \mathrm{E} 010$ nolu, "Termoelektrik Soğutucuların Yağlı Tip Dağıtım Transformatörlerinin Faydalı Ömürlerine Etkisinin İncelenmesi” adlı projenin sağladığı destekle tamamlanmış olup yazarlar TÜBİTAK'a teşekkürü bir borç bilirler. 


\section{Kaynakça}

Ab Ghani, S., Muhamad, N. A., Noorden, Z. A., Zainuddin, H., Abu Bakar, N., \& Talib, M. A. (2018). Methods for improving the workability of natural ester insulating oils in power transformer applications: A review. Electric Power Systems Research, 163, 655-667. doi: 10.1016/J.EPSR.2017.10.008

Ahiska, R., Ahiska, G., \& Ahiska, K. (2009). Analysis of a New Method for Measurement of Parameters of Real Thermoelectric Module Employed in Medical Cooler for Renal Hypothermia. Instrumentation Science and Technology, 37(1), 102-123. doi: $10.1080 / 10739140802584772$

Ahıska, R., \& Ahıska, K. (2013). Esnek İki Fazlı Termoelektrik CPU Soğutucusu. Journal of the Faculty of Engineering and Architecture of Gazi University, 22(2), 347-351. Retrieved

from

https://dergipark.org.tr/en/pub/gazimmfd/88383

Cai, Y., Wang, Y., Liu, D., \& Zhao, F. Y. (2019). Thermoelectric cooling technology applied in the field of electronic devices: Updated review on the parametric investigations and model developments. Applied Thermal Engineering, 148, 238-255.

10.1016/J.APPLTHERMALENG.2018.11.014

doi:

Cuce, E., Guclu, T., \& Cuce, P. M. (2020). Improving thermal performance of thermoelectric coolers (TECs) through a nanofluid driven water to air heat exchanger design: An experimental research. Energy Conversion and Management, 214, $112893 . \quad$ doi: 10.1016/j.enconman.2020.112893

Dalcali, A., \& Demirel, H. (2016). Microcontroller-based cooling of a single-phase transformer with thermoelectric module. The International Journal of Energy and Engineering Sciences, 1(2), 4-14. Retrieved from https://dergipark.org.tr/en/pub/ijees/612249

Dmitriev, A. V., Dmitrieva, O. S., \& Madyshev, I. N. (2017). Prospects for the Use of Additional Cooling System for the Oil-Immersed Transformers with Thermoelectric Transducers. MATEC Web of Conferences, 95, 15012. doi: $10.1051 /$ matecconf $/ 20179515008$

Dombek, G., Goscinski, P., \& Nadolny, Z. (2017). Comparison of mineral oil and esters as cooling liquids in high voltage transformer in aspect of environment protection. E3S Web of Conferences, 14, $01053 . \quad$ doi: 10.1051/E3SCONF/20171401053

Filho, A. A. P., Luna, F. M. T., \& Cavalcante, C. L. (2019). Oxidative stability of mineral naphthenic insulating oils: Optimization of commercial antioxidants and metal passivators. IEEE Transactions on Dielectrics and Electrical Insulation, 26(1), 240-246. doi: 10.1109/TDEI.2018.007513

Garelli, L., Ríos Rodriguez, G. A., Kubiczek, K., Lasek, P., Stepien, M., Smolka, J., Storti, M., Pessolani, F., \& Amadei, M. (2021). Thermo-magnetic-fluid dynamics analysis of an ONAN distribution transformer cooled with mineral oil and biodegradable esters. Thermal Science and Engineering Progress, 23, 100861. doi: 10.1016/J.TSEP.2021.100861
Hasan, M. I., Ugla, A. A., \& Kadhim, H. S. (2020). Improving the thermal performance of electrical transformers using hybrid mixture of (transformer oil, nanoparticles, and PCM). AlQadisiyah Journal for Engineering Sciences, 13(3), 175182. doi: 10.30772/QJES.V13I3.704

Hsin, C. L., Wu, M. H., \& Wang, W. C. (2019). Thermoelectric Devices by Half-Millimeter-Long Silicon Nanowires Arrays. IEEE Transactions on Nanotechnology, 18, 921924. doi: 10.1109/TNANO.2019.2938624

Hubbard, W. A., Mecklenburg, M., Lodico, J. J., Chen, Y., Ling, X. Y., Patil, R., Kessel, W. A., Flatt, G. J. K., Chan, H. L., Vareskic, B., Bal, G., Zutter, B., \& Regan, B. C. (2020). Electron-Transparent Thermoelectric Coolers Demonstrated with Nanoparticle and Condensation Thermometry. ACS Nano, 14(9), 11510-11517. doi: 10.1021/acsnano.0c03958

Jiang, L., Zhang, H., Li, J., \& Xia, P. (2019). Thermal performance of a cylindrical battery module impregnated with PCM composite based on thermoelectric cooling. Energy, 188, 116048 . doi: 10.1016/J.ENERGY.2019.116048

Kaymaz, O., Kalkan, G., \& Erek, A. (2015). Flow and heat transfer characteristics of different transformer oils in one section of transformer radiator. Mühendis ve Makina, 56(666), 53-63. Retrieved from https://dergipark.org.tr/en/pub/muhendismakina/736101

Koh, Y. R., Yazawa, K., \& Shakouri, A. (2014). Cooling heat flux, COP, and cost optimization of integrated thermoelectric microcoolers with variation of thermoelectric properties. Thermomechanical Phenomena in Electronic Systems Proceedings of the Intersociety Conference, 1412-1416. doi: 10.1109/ITHERM.2014.6892445

Lamarre, C., Crine, J. P., \& Duval, M. (1987). Influence of oxidation on the electrical properties of inhibited naphthenic and paraffinic transformer oils. IEEE Transactions on Electrical Insulation, EI-22(1), 57-62. doi: 10.1109/TEI.1987.298965

Manjang, S., Kitta, I., \& Ikhlas, A. (2019, October 1). Voltage Breakdown Characteristics of Transformer Mineral Oil with Varies the Composition of Corn Oil. Proceedings of the 2nd International Conference on High Voltage Engineering and Power Systems: Towards Sustainable and Reliable Power Delivery, ICHVEPS 2019. doi: 10.1109/ICHVEPS47643.2019.9011119

Perez, J. (2010). Fundamental principles of transformer thermal loading and protection. 63rd Annual Conference for Protective Relay Engineers. doi: 10.1109/CPRE.2010.5469518

Rao, U. M., Pulluri, H., \& Kumar, N. G. (2018). Performance analysis of transformer oil/paper insulation with ester and mixed dielectric fluids. IEEE Transactions on Dielectrics and Electrical Insulation, 25(5), 1853-1862. doi: 10.1109/TDEI.2018.007224

Rouabeh, J., M'barki, L., Hammami, A., Jallouli, I., \& Driss, A. (2019). Studies of different types of insulating oils and their mixtures as an alternative to mineral oil for cooling power transformers. Heliyon, 5(3), e01159. doi: 10.1016/j.heliyon.2019.e01159 
Sekiguchi, R., Liu, Y., \& Sano, Y. (2018). Thermal Equivalent Circuit of Peltier Device Considered Seebeck Effect and Driving Method Improving Cooling Efficiency of the Device. Electronics and Communications in Japan, 101(5), 73-83. doi: 10.1002/ecj.12065

Shell Diala S4 ZX-I Trafo Yă̆ı. (n.d.). Retrieved from https://solutions.shell.com/in/products/Diala_S4_ZXI $\quad 001 \mathrm{E} 8701$

Specification of Thermoelectric Module. (n.d.). Retrieved from http://www.thermonamic.com/TEC1-12706-English20201124.pdf

Toren, M., \& Celebi, M. (2016). Impact on efficiency of core materials in dry type transformers. 2016 National Conference on Electrical, Electronics and Biomedical Engineering, 170-173.

Toren, M., \& Mollahasanoglu, H. (2021). Investigation of thermoelectric cooler system effect on induction motor performance. 2021 17th Conference on Electrical
Machines, Drives and Power Systems, ELMA 2021 Proceedings. doi: 10.1109/ELMA52514.2021.9503049

Trafo Yăgl. (n.d.). Retrieved from http://speedol.com.tr/trafoyagi/

Wang, X., \& Wang, Z. D. (2008). Particle effect on breakdown voltage of mineral and ester based transformer oils. Annual Report - Conference on Electrical Insulation and Dielectric Phenomena, CEIDP, 598-602. doi: 10.1109/CEIDP.2008.4772859

Wang, Xiaobo, Tang, C., Huang, B., Hao, J., \& Chen, G. (2018). Review of Research Progress on the Electrical Properties and Modification of Mineral Insulating Oils Used in Power Transformers. Energies, 11(3), $487 . \quad$ doi: 10.3390/EN11030487 